\title{
Metode Activity Based Costing dalam Penentuan Unit Cost Eksisi Fibroadenoma Mammae
}

\author{
Afiazka Luthfita ${ }^{1^{*}}$ \& Susanto $^{2}$ \\ *Penulis Korespondensi: afiazkaluthfita@gmail.com \\ Magister Manajemen Rumah Sakit Universitas Muhammadiyah Yogyakarta

\begin{tabular}{l}
\hline $\boldsymbol{I} \boldsymbol{N D E} \boldsymbol{X I N G}$ \\
\hline Keywords: \\
Activity Based \\
Costing (ABC), breast \\
fibroadenoma (FAM), \\
Unit cost
\end{tabular}

\begin{abstract}
A B S T R A C T
Indonesian began to operate health insurance program on 2014 with payment scheme by INA-CBG's (Indonesian Case Based Group). That make hospital to have appropriate tariff calculation. Breast fibroadenoma (FAM)must have appropriate tariff calculation because it will be increasing. One of calculating method that can be used is Activity Based Costing (ABC) because this method can measure accurately cost out of any activity, improve the precision and accuracy in the details of charging fees. This study was descriptive quantitative. This study is limited to patient with FAM cases that occurred in 2015 in patients using BPJS class III and without complications. The unit cost of service excision FAM still under INA-CBG's rates, calculations by the ABC method is higer than the unit cost PKU Muhammadiyah Hospital. The management should be re-evaluated the tarif of this service.
\end{abstract}

(C) 2016 JMMR. All rights reserved

Article history: received 25 Jul 2016; revised 19 Okt 2016; accepted 25 Nov 2016

\section{PENDAHULUAN}

Pemerintah Indonesia melalui kementerian kesehatan di awal tahun 2014, mulai mengoperasikan program Jaminan Kesehatan Nasional (JKN). Program JKN diselenggarakan oleh Badan Penyelenggara Jaminan Sosial (BPJS) sesuai dengan UU No.24 tahun 2011 tentang BPJS. JKN merupakan salah satu upaya pemerintah dalam meningkatkan pelayanan kesehatan bagi seluruh warga negara Indonesia.

Bagian terpenting dalam implementasi JKN adalah pembiayaan kesehatan. Pembiayaan kesehatan bertujuan mendorong peningkatan mutu, pelayanan berorientasi pasien, efisiensi, dan terbentuknya pelayanan tim. Tujuan tersebut diharapkan bisa dicapai dengan pembiayaan yang tepat ${ }^{2}$. Dalam implementasi Jaminan Kesehatan Nasional (JKN) telah diatur pola pembayaran kepada fasilitas kesehatan tingkat lanjutan berdasarkanINA-CBG's(Indonesian Case Based Group). INA-CBG's merupakan pola pembayaran prospektif berdasarkan pendekatan system casemix. Casemix adalah sistem pengelompokkan penyakit yang menggabungkan antara biaya perawatan dengan jenis penyakit di rumah sakit ${ }^{3}$.

Salah satu penyakit yang membutuhkan penghitungan biaya dengan tepat adalah fibro adenoma mammae (FAM). FAM merupakan tumor jinak payudara yang biasa terjadi pada wanita dewasa berusia kurang dari 25 tahun. FAM dapat didiagnosis berdasarkan karakteristik klinis pada 50\%-67\% kasus, namun diperlukan pula pemeriksaan diagnostik tambahan untuk menegakkan diagnosis ${ }^{4}$.

Berdasarkan data World Health Organitation (WHO) pada tahun 2030 akan terjadi lonjatan penderita kanker di Indonesia sampai tujuh kali lipat. Daerah penderita kanker terbanyak di Indonesia adalah Yogyakarta dengan tingkat prevelensi 9,6 per $1.000^{6}$.

Rumah sakit sebagai fasilitas kesehatan tingkat lanjutan dituntut melakukanefisiensi pelaksanaannya, sehingga ketepatan perhitungan biaya-biaya sangatlah penting. Rumah Sakit PKU Muhammadiyah Yogyakarta sebagai salah satu rumah sakit tipe B di Daerah Istimewa Yogyakarta perlu melakukan penghitungan biaya yang tepat. Hal ini dikarenakan jumlah pasien FAM pada rumah sakit tersebut mengalami kenaikan setiap tahunnya.

Agar dapat menghitung unit cost layanan rumah sakit, terdapat sebuah metode penentuan berdasarkan aktivitas yang dirancang untuk mengatasi distorsi pada akuntansi biaya tradisional yang disebut metode $\mathrm{ABC}$ (Activity Based Costing). Metode $\mathrm{ABC}$ mengukur secara cermat biaya dari setiap aktivitas sesuaicost 
driver yang menyebabkan biaya tersebut terjadi. Metode $\mathrm{ABC}$ lebih akurat melakukan pembebanan biaya lebih ${ }^{7}$. Perhitungan yang akurat mengenai biaya eksisi FAM ini dapat dijadikan sebagai dasar pemanfaatan tindakan tersebut sebagai salah satu sumber pemasukan di RS PKU Muhammadiyah Unit 1 mengingat akan terjadinya kenaikan prevalensi.

Berdasarkan uraian di atas penelitian ini dilakukan untuk mengetahui: Berapakah biaya satuan layanan fibroadenoma mamae disertai tindakan eksisi tumor pada Rumah Sakit PKU Muhammadiyah Yogyakarta?dan Bagaimana analisis selisih antara hasil perhitungan biaya satuan layanan fibroadenoma mammae disertai tindakan eksisi dengan metode activity based costing dengan perhitungan rumah sakit dan tarif INA-CBG'sdi RS PKU Muhammadiyah Yogyakarta?

\section{METODE PENELITIAN}

Jenis penelitian ini adalah deskriptif kuantitatif yaitu data yang diperoleh dari sampel populasi dianalisis dengan menggunakan metode kuantitatif yang kemudian diinterpretasikan (Sugiyono, 2013). Subjek penelitian adalah Kepala Bagian Keuangan, Dokter Spesialis Bedah, Kepala Ruang Instalasi Bedah Sentral, petugas administrasi seperti petugas pendaftaran, rekam medis, bagian mutu, bagian pemasaran dan kesekertariatan Rumah Sakit PKU Muhammadiyah Yogyakarta. Objek penelitian adalah aktivitas yang dilakukan untuk menghasilkan produk layanan jasa di pelayanan eksisi fibro adenoma mammae di RS PKU Muhammadiyah Yogyakarta. Aktivitas yang dimaksud adalah semua aktivitas yang terjadi pada layanan eksisi fibroadenoma mammae baik langsung maupun penunjang yang mendukung aktivitas layanan eksisi fibroadenoma mammae.

Variabel penelitian adalah biaya satuan akomodasi yang terjadi pada pasien yang mendapatkan layanan eksisi fibroadenoma mammae dan aktivitas di unit rawat jalan bedah, Rawat Inap, Instalasi Bedah Sentral, Gizi, Instalasi Laboratorium, Instalasi Radiologi, Bagian Keuangan dan kasir. Instrumen penelitian pada penelitian terdiri dari: (a) Pedoman dokumentasi yaitu prosedur yang terkait dengan pelayanan eksisi fibroadenoma mammae yang dimiliki
RS PKU Muhammadiyah Yogyakarta. (b) Pedoman wawancara. Responden yang diwawancara terdiri dari kepala bagian keuangan, kepala perawat ruang bedah sentral, perawat bedah sentral, cleaning service, pegawai laundri, serta pegawai administrasi RS PKU Muhammadiyah Yogyakarta.Wawancara mendalam dilakukan dalam panduan wawancara yang sudah ditentukan ataupun pertanyaan yang bersifat spontan muncul saat interview berlangsung. Data yang diperoleh berupa gambaran umum mengenai RS PKU Muhammadiyah Yogyakarta, sistem yang digunakan oleh rumah sakit dalam mnentukan biaya pelayanan eksisi fibroadenoma mammae dan identifikasi aktivitas yang dilakukan pada layanan eksisi fibroadenoma mammae. (c) Panduan observasi menggunakan checklist dalam clinical pathway. Pengamatan langsung dilakukan pada objek penelitian, yaitu aktivitas yang dilakukan selama pasien di rawat. (d) Stopwatch adalah alat pengukur waktu yang digunakan untuk mengukur lamanya waktu setiap aktivitas yang dilakukan, mulai dari pasien mendaftar sampai pasien keluar dari rumah sakit.

Penelitian menggunakan data primer dan data sekunder. Data primer adalah data yang diperoleh langsung dari sumber yang berhubungan, seperti wawancara dengan bagian keuangan untuk mendapatkan gambaran tentang penetapan biaya layanan eksisi fibroadenoma mammae RS PKU Muhammadiyah Yogyakarta. Selain itu juga dilakukan wawancara untuk mendapatkan gambaran aktivitas yang dilakukan pada layanan eksisi fibroadenoma mammae. Peneliti juga melakukan observasi langsung ke ruang instalasi bedah sentral untuk mendapatkan data mengenai luas ruangan serta fasilitas yang ada.

Adapun langkah-langkah sebagai berikut; (a) Aktifitas diidentifikasikan dan didefinisikan melalui data primer (wawancara dan observasi) dan data Membuat daftar aktivitas dan penggerak aktivitas. (b) Klasifikasi aktivitas sebagai aktivitas primer dan aktivitas sekunder kemudian menggambarkan tugas yang menyebabkan aktivitas. (c) Identifikasi cost driver untuk mrnghubungkan aktivitas utama ke produk. 


\section{HASIL DAN PEMBAHASAN}

\section{Jenis Dan Rancangan Penelitian}

Jenis penelitian ini adalah deskriptif kuantitatif yaitu data yang diperoleh dari sampel populasi dianalisis dengan menggunakan metode kuantitatif yang kemudian diinterpretasikan (Sugiyono, 2013).

\section{Subjek dan Objek Penelitian}

Subjek penelitian adalah Kepala Bagian Keuangan, Dokter Spesialis Bedah, Kepala Ruang Instalasi Bedah Sentral, petugas administrasi seperti petugas pendaftaran, rekam medis, bagian mutu, bagian pemasaran dan kesekertariatan Rumah Sakit PKU Muhammadiyah Yogyakarta. Objek penelitian adalah aktivitas yang dilakukan untuk menghasilkan produk layanan jasa di pelayanan eksisi fibro adenoma mammae di RS PKU Muhammadiyah Yogyakarta. Aktivitas yang dimaksud adalah semua aktivitas yang terjadi pada layanan eksisi fibroadenoma mammae baik langsung maupun penunjang yang mendukung aktivitas layanan eksisi fibroadenoma mammae.

Variabel penelitian adalah biaya satuan akomodasi yang terjadi pada pasien yang mendapatkan layanan eksisi fibroadenoma mammae dan aktivitas di unit rawat jalan bedah, Rawat Inap, Instalasi Bedah Sentral, Gizi, Instalasi Laboratorium, Instalasi Radiologi, Bagian Keuangan dan kasir.

\section{Instrumen Penelitian}

Instrumen penelitian pada penelitian terdiri dari; (a) Pedoman dokumentasi yaitu prosedur yang terkait dengan pelayanan eksisi fibroadenoma mammae yang dimiliki RS PKU Muhammadiyah Yogyakarta. (b) Pedoman wawancara. Responden yang diwawancara terdiri dari kepala bagian keuangan, kepala perawat ruang bedah sentral, perawat bedah sentral, cleaning service, pegawai laundri, serta pegawai administrasi RS PKU Muhammadiyah Yogyakarta.Wawancara mendalam dilakukan dalam panduan wawancara yang sudah ditentukan ataupun pertanyaan yang bersifat spontan muncul saat interview berlangsung. Data yang diperoleh berupa gambaran umum mengenai RS PKU Muhammadiyah Yogyakarta, sistem yang digunakan oleh rumah sakit dalam mnentukan biaya pelayanan eksisi fibroadenoma mammae dan identifikasi aktivitas yang dilakukan pada layanan eksisi fibroadenoma mammae. (c) Panduan observasi menggunakan checklist dalam clinical pathway.Pengamatan langsung dilakukan pada objek penelitian, yaitu aktivitas yang dilakukan selama pasien di rawat. (d) Stopwatch adalah alat pengukur waktu yang digunakan untuk mengukur lamanya waktu setiap aktivitas yang dilakukan, mulai dari pasien mendaftar sampai pasien keluar dari rumah sakit.

\section{Analisis Data}

Penelitian menggunakan data primer dan data sekunder. Data primer adalah data yang diperoleh langsung dari sumber yang berhubungan, seperti wawancara dengan bagian keuangan untuk mendapatkan gambaran tentang penetapan biaya layanan eksisi fibroadenoma mammae RS PKU Muhammadiyah Yogyakarta. Selain itu juga dilakukan wawancara untuk mendapatkan gambaran aktivitas yang dilakukan pada layanan eksisi fibroadenoma mammae. Peneliti juga melakukan observasi langsung ke ruang instalasi bedah sentral untuk mendapatkan data mengenai luas ruangan serta fasilitas yang ada.

Adapun langkah-langkah sebagai berikut: (a) Aktifitas diidentifikasikan dan didefinisikan melalui data primer (wawancara dan observasi) dan data Membuat daftar aktivitas dan penggerak aktivitas. (b) Klasifikasi aktivitas sebagai aktivitas primer dan aktivitas sekunder kemudian menggambarkan tugas yang menyebabkan aktivitas. 
Identifikasi cost driver untuk mrnghubungkan aktivitas utama ke produk

Tabel 1. Biaya Langsung Pelayanan Eksisi Fibro Adenoma Mammae RS PKU Muhammadiyah Yogyakarta tahun 2014

\begin{tabular}{|c|c|c|c|c|}
\hline Kategori Biaya & Satuan & Jumlah Satuan & Biaya Satuan & Jumlah \\
\hline \multicolumn{5}{|l|}{ Pelayanan Poli } \\
\hline Pendaftaran & Aktivitas & 1 & 18,000 & 18,000 \\
\hline Konsultasi Spesialis Bedah Umum & Tindakan & 1 & 49,500 & 49,500 \\
\hline \multicolumn{5}{|l|}{ Pelayanan Ibs } \\
\hline Tindakan Operasi Sedang & & 1 & $1,404,000$ & $1,404,000$ \\
\hline Sterilisasi Alat & Alat & 1 & 162,000 & 162,000 \\
\hline Laundry & $\mathrm{Kg}$ & 4,5 & 4,500 & 20,250 \\
\hline \multicolumn{5}{|l|}{ Obat Dan Bahan Habis Pakai } \\
\hline Spuit Terumo $2,5 \mathrm{Cc}$ & Pcs & 1 & 3,600 & 3,600 \\
\hline Spuit Terumo $5 \mathrm{Cc}$ & Pcs & 1 & 4,410 & 4,410 \\
\hline Spuit Terumo $10 \mathrm{Cc}$ & Pcs & 1 & 5,760 & 5,760 \\
\hline Ringer Lactate 500ml & $\mathrm{Flb}$ & 4 & 11,700 & 46,800 \\
\hline Lma Ambu 30.35 Pieces & Pcs & 1 & 106,380 & 106,380 \\
\hline Clopedin Inj 1 Ampul & Amp & 1 & 29,160 & 29,160 \\
\hline Ondansetron $4 \mathrm{mg} / 2 \mathrm{ml}$ & Amp & 1 & 8,730 & 8,730 \\
\hline Recofol N 20mg/Ml & Vial & 1 & 100,260 & 100,260 \\
\hline Tramadol Inj & Amp & 1 & 7,290 & 7,290 \\
\hline Terrel 250ml $30 \mathrm{Cc}$ & $\mathrm{Cc}$ & 30 & 6,930 & 207,900 \\
\hline N2o $25 \mathrm{Kg} 200 \mathrm{Cc}$ & $\mathrm{Cc}$ & 200 & 116.55 & 23,310 \\
\hline O2 Kap 6200 Cc & $\mathrm{Cc}$ & 200 & 12.6 & 2,520 \\
\hline Under Pads 1 Pieces & Pcs & 1 & 3,420 & 3,420 \\
\hline Aquadest Opls 25cc & $\mathrm{Flb}$ & 3 & 3,600 & 10,800 \\
\hline Braunol Sol $100 \mathrm{Cc}$ & $\mathrm{Cc}$ & 100 & 143.1 & 14,310 \\
\hline Alkohol 70\%/Cc $100 \mathrm{Cc}$ & $\mathrm{Cc}$ & 100 & 31.5 & 3,150 \\
\hline Mess Aesculap No. 23 & Pcs & 1 & 3,060 & 3,060 \\
\hline Daryantulle\# 1 Pieces & Pcs & 1 & 18,630 & 18,630 \\
\hline Kasa Lipat 5 Cmx $13 \mathrm{~cm} x 12$ Ply & Pcs & 30 & $1,023.03$ & 30,690 \\
\hline Daryantulle\# 0.5 Pieces & Pcs & 1 & 9,360 & 9,360 \\
\hline Handscoend St 7,5 Gamex & Pcs & 1 & 35,910 & 35,910 \\
\hline Handscond St 7 Maxter/Winiche & Pcs & 1 & 7,020 & 7,020 \\
\hline Catgut Chr 2/0 Cg-811/Cg 923 & Pcs & 1 & 79,830 & 79,830 \\
\hline Dermalon 2-0 1727-51 & Pcs & 1 & 74,880 & 74,880 \\
\hline Pot Salep 100gr & Pcs & 1 & 1,170 & 1,170 \\
\hline Paket Eksterpasi & Pcs & 1 & 185,670 & 185,670 \\
\hline Ceftriaxone 1gr Inj & Amp & 1 & 43,020 & 43,020 \\
\hline Ketorolac 30mg Inj 4 & Vial & 1 & 60,210 & 60,210 \\
\hline Cyprofloxacin 500mg & $\mathrm{Tab}$ & 10 & 414 & 4,140 \\
\hline Natrium Diclovenax $50 \mathrm{Mg}$ & $\mathrm{Tab}$ & 10 & 252 & 2,520 \\
\hline \multicolumn{5}{|l|}{ Pelayanan Marwah } \\
\hline Visite Dokter Spesialis Bedah & Tindakan & 4 & 63,000 & 252,000 \\
\hline Visite Dokter Spesialis Anestesi & Tindakan & 2 & 63,000 & 126,000 \\
\hline Pemasangan Infus & Tindakan & 1 & 16,200 & 16,200 \\
\hline Injeksi & Tindakan & 3 & 9,900 & 29,700 \\
\hline \multicolumn{5}{|l|}{ Laboratorium } \\
\hline Ekg & Tindakan & 1 & 27,000 & 27,000 \\
\hline Rongent Thorax & Tindakan & 1 & 87,120 & 87,120 \\
\hline Pemeriksaan Darah Rutin & Tindakan & 1 & 49,500 & 49,500 \\
\hline Hbsag & Tindakan & 1 & 45,000 & 45,000 \\
\hline Ptt & Tindakan & 1 & 51,300 & 51,300 \\
\hline Aptt & Tindakan & 1 & 51,300 & 51,300 \\
\hline Gds & Tindakan & 1 & 16,200 & 16,200 \\
\hline PA Jaringan & Tindakan & 1 & 243,000 & 243,000 \\
\hline Total & & & & $3,781,980$ \\
\hline
\end{tabular}

Sumber : RS PKU Muhammadiyah Yogyakarta 2014 
Tabel 2. Total Biaya Overhead RS PKU Muhammadiyah Tahun 2014

\begin{tabular}{|c|c|c|c|}
\hline \multirow[t]{2}{*}{ Unit Rumah Sakit } & \multicolumn{2}{|l|}{ Biaya Overhead } & \multirow[b]{2}{*}{ Total Biaya Overhead ${ }^{(c)}(\mathrm{Rp})$} \\
\hline & $\begin{array}{c}\text { Indirect Resource }{ }^{(a)} \\
\text { (Rp) }\end{array}$ & $\begin{array}{c}\text { Direct Resource }^{(b)} \\
\text { (Rp) }\end{array}$ & \\
\hline Klinik Bedah Umum & 20,877 & 6331 & 27,208 \\
\hline Bangsal Marwah & 46,528 & 99,716 & 146,244 \\
\hline Instalasi Bedah Sentral & 220,948 & 108,783 & 329,731 \\
\hline
\end{tabular}

Tabel 3.Unit Cost EKsisi Fibro Adenoma Mammae RS PKU

Muhammadiyah Yogyakarta

\begin{tabular}{lcc}
\multicolumn{1}{c}{ Struktur Biaya } & Biaya (Rp) & Total (Rp) \\
\hline Biaya Langsung eksisi FAM & & $3,781,980$ \\
& Indirect & Direct Resource \\
Biaya Overhead & Resource & Overhead \\
& Overhead & 6,331 \\
Biaya overheadeksisi FAM di Klinik Bedah Umum & 20,877 & 385,896 \\
Biaya overheadeksisi FAM di Bangsal Marwah & 180,061 & 108,783 \\
Biaya overhead eksisi FAM di IBS & 220,948 & 565,957 \\
Total Seluruh Biaya & & 329,731 \\
\hline
\end{tabular}

a. Menentukan biaya direct resource overhead dan indirect resource overheadpada unit klinik bedah umum, kamar operasi, dan bangsal Marwah. Biaya overhead dikelompokkan menjadi empat kategori yaitu labor related, equipment related, space related, dan service related. Hasil perhitungan biaya setiap unit terkait dapat terlihat pada tabel 2.

b. Menentukan biaya indirect resourcedan direct resource overhead setiap aktivitas berdasarkan waktu dan activity centerpada unit yang terkait.

c. Menjumlahkan seluruh biaya langsung dan overhead pada tindakan eksisi fibroadenoma mammae yang sesuai dengan clinical pathway.

\section{Pembahasan}

\section{Beban Biaya dalam Perhitungan Unit Cost Tindakan Eksisi Fibro Adenoma Mammae}

Berdasarkan perhitungan dengan metode $\mathrm{ABC}$ didapatkan unit cost untuk tindakan eksisi fibroadenoma mammae adalah sebesar $\mathrm{Rp}$ 4,704,877. Beban biaya yang terlibat pada unit cost tindakan eksisi fibroadenoma mammae terdiri dari: (a) Beban biaya langsung dalam perhitungan unit cost tindakan eksisi fibroadenoma mammae.
Biaya langsung pada tindakan eksisi fibroadenoma mammae sebesar $\mathrm{Rp}$ 3,781,980 atau sebesar $80 \%$ dari total beban biaya unit cost tindakan tersebut. Tingginya beban biaya langsung dikarenakan banyaknya jasa medis dokter spesialis, bahan habis pakai yang digunakan, dan prosedur pemeriksaan yang harus dilakukan pasien sebelum melakukan operasi.

Berdasarkan laporan dari bagian penetapan biaya RS PKU Muhammadiyah Yogyakarta direct cost pasien eksisi fibroadenoma mammae berbeda-beda. Perbedaan direct cost terletak pada biaya obat-obat anastesi serta bahan medis habis pakai. Hal ini dikarenakan setiap pasien memiliki perbedaan ukuran tumor serta lama waktu pengerjaan tindakaan operasi tersebut. Kepatuhan dokter terhadap clinical pathway dan penggunaan obat sesuai formularium dalam melakukan tindakan eksisi fibroadenoma mammae pada pasien BPJS kelas III sangat berpengaruh terhadap mutu tindakan serta efisiensi biaya di rumah sakit8.

Jasa medis dokter yang dibebankan pada pasien juga mengkonsumsi biaya yang cukup besar. Jasa medis yang dibebankan ini meliputi biaya konsultasi ketika di poliklinik bedah umum, visite pre operasi, visite post operasi, jasa tindakan operasi fibroadenoma mammae, dan anestesi di kamar operasi. Rumah sakit hanya memberikan jasa dokter untuk tindakan BPJS kelas III sebesar $50 \%$ dari jasa medis pasien umum 
lainnya, sehingga dalam hal ini sulit untuk dilakukan efisiensi biaya. (b) Beban Biaya overhead dalam perhitungan unit cost

Biaya overhead pada tindakan eksisi fibroadenoma mammae sebesar Rp 922,897 atau 19,6\% dari beban keseluruhan biaya tindakan eksisi fibroadenoma mammae. Biaya overhead ini terbagi dalam biaya overhead poliklinik bedah umum yaitu sebesar Rp 27,208 (0,6\%), bangsal Marwah Rp 565,957 (12\%), dan kamar operasi Rp 329,731 (7\%).

Berdasarkan perhitungan yang telah dilakukan didapatkan biaya indirect resource overhead pada klinik bedah umum adalah sebesar Rp 20,877 sedangkan biaya direct resource overhead klinik bedah umum sebesar Rp 6,331. Biaya yang dibebankan pada unit ini hanya sebesar $0,6 \%$ dari keseluruhan biaya tindakan eksisi fibroadenoma mammae. Kecilnya biaya yang dibebankan ini karena pasien hanya menikmati layanan di poli bedah umum untuk melakukan konsultasi serta pemeriksaan fisik yang menunjang diagnosis.

Pembebanan biaya overhead pada unit rawat inap Marwah sebesar $12 \%$ dari keseluruhan biaya tindakan eksisi fibroadenoma mammae, dengan rincian biaya indirect resource overhead sebesar Rp 180,061 dan biaya direct resource overhead Rp 385,896. Pada unit rawat inap ini banyak fasilitas yang terlibat pada tindakan eksisi fibroadenoma mammae meliputi persiapan pasien sebelum melakukan operasi dan perawatan yang dibutuhkan sesudah operasi, sehingga bila dibandingkan dengan unit lain pembebanan biaya overhead pada unit ini lebih tinggi dibandingkan dengan unit rawat jalan dan kamar operasi.

Biaya overhead unit kamar operasi dibebankan sebesar 7\% dari keseluruhan biaya tindakan eksisi fibroadenoma mammae. Biaya overhead unit ini meliputi biaya indirect sebesar Rp 220,948 dan direct sebesar Rp 108,783. Pada unit ini prosedur operasi dilakukan pada pasien sehingga jumlah biaya indirect resource overhead paling besar dibandingkan 2 unit lainnya karena dihitung berdasarkan persentase pendapatan unit IBS, jumlah dan jenis operasi yang dilakukan. Operasi eksisi fibroadenoma mammae termasuk dalam operasi sedang serta unit ini merupakan unit ke-2 yang menyumbangkan persentase pendapatan tertinggi sehingga berdasarkan perhitungan pembebanan yang dilakukan oleh RS PKU Muhammadiyah Yogyakarta biaya yang dibebankan pada pasien cukup besar.

Biaya indirect resources overhead mencerminkan besarnya biaya pada unit-unit non fungsional. Unitunit non fungsional yang ada di RS PKU Muhammadiyah meliputi direksi, diklat, pengadaan, keamanan, kendaraan, dll. Jumlah tenaga kerja pada unit non fungsional ini adalah 134 pegawai atau 30\% dari total pegawai yang ada di RS PKU Muhammadiyah Yogyakarta yaitu 570 pegawai. ${ }^{9}$

Berdasarkan metode activity based cost unit rawat jalan dan kamar operasi menunjukan biaya indirect lebih besar, hal ini menunjukkan besarnya biaya yang dikeluarkan unit non fungsional. Biaya yang menghabiskan dana besar pada unit non fungsional ini terletak pada biaya gaji pegawai, pemakaian barang pengadaan dan biaya kantor serta langganan. Tingginya biaya pada unit non fungsional menunjukkan adanya biaya yang tidak efisien pada unit-unit tersebut.

Direct resource overhead sebagian besar mencerminkan biaya para pegawai yang turut serta secara langsung dalam proses perawatan pasien serta service related cost. Berdasarkan data yang diperoleh jumlah perawat adalah 241 dengan jumlah tempat tidur 205, hal ini telah sesuai dengan peraturan pemerintah yaitu perbandingan perawat dan tempat tidur adalah 1:1 10. Biaya-biaya yang berkaitan dengan service related menghabiskan biaya yang cukup besar berkaitan dengan barang habis pakai yang digunakan.

\section{Unit Cost Tindakan Eksisi Fibro Adenoma Mammae Melalui Perhitungan Activity Based Costing dan Unit Coct RS PKU Muhammadiyah Yogyakarta}

Unit cost pelayanan eksisi fibro adenoma mammae dengan perhitungan metode $\mathrm{ABC}$ didapatkan sebesar Rp 4,704,877, sedangkan perhitungan rumah sakituntuk pelayanan tersebut di adalah sebesar Rp $4,431,420$. Unit cost dengan metode perhitungan yang berbeda ini masih lebih rendah dibandingkan dengan claim BPJS yaitu sebesar Rp 5,384,348. 
Tabel 4 Selisih Antara Unit Cost ABC, Unit Cost RS, dan Tarif INA CBG's Tindakan Eksisi Fibro Adenoma Mammae Tahun 2014

\begin{tabular}{lll}
\hline Perbandingan Antara Unit Cost ABC Dan RS & & \\
\hline Unit Cost ABC (Rp) & Unit Cost RS (Rp) & Selisih \\
$4,704,877$ & $4,431,420$ & 273,457 \\
Perbandingan Antara Unit Cost ABC Dan INA-CBG's & & \\
Unit Cost ABC (Rp) & Tarif INACBG (Rp) & Selisih \\
$4,704,877$ & $5,384,348$ & 679,471 \\
Perbandingan Antara Unit Cost RS Dan INA-CBG'S & & \\
Unit Cost RS(Rp) & Tarif INACBG (Rp) & Selisih \\
$4,431,420$ & $5,384,348$ & 952,928 \\
\hline
\end{tabular}

Pada perhitungan didapatkan selisih antara unit cost RS dan unit cost ABC sebesar Rp 273,457. Perbedaan biaya ini berdasarkan data yang diperoleh terletak pada jenis obat anastesi serta jenis tindakan yang dituliskan oleh dokter bedah. Pada clinical pathway eksisi FAM tindakan yang dilakukan termasuk pada operasi sedang akan tetapi pada beberapa data jenis tindakan yang tertulis adalah eksisi besar. Selain itu pada perhitungan dengan activity based costing dibebankan biaya depresiasi bangunan, sedangkan pada perhitungan tradisional tidak bebankan biaya depresiasi.

Pada perbandingan biaya pelayanan eksisi fibro adenoma mammae dengan metode $\mathrm{ABC}$ masih lebih rendah dibandingkan dengan tarif yang ditetapkan oleh pemerintah untuk tindakan tersebut yaitu sebesar $\mathrm{Rp}$ $5,384,348$. Keuntungan yang diperoleh rumah sakit sebagai penyedia layanan ini adalah sebesar $\mathrm{Rp}$ 952,928 bila dibandingkan dengan perhitungan rumah sakit, sedangkan bila dibandingkan dengan perhitungan ulang dengan metode $\mathrm{ABC}$ adalah sebesar $\mathrm{Rp}$ 679,471 . Pemanfaatan metode penetapan biaya pada rumah sakit tidak sama dengan sektor organisasi bisnis lainnya. Ekonomi rumah sakit sangat sering didasarkan pada pendanaan publik dan tujuan utama dari organisasi ini jauh lebih untuk memberikan pelayanan kesehatan yang sesuai dengan tarif yang ditetapkan, daripada menghasilkan keuntungan. Hal tersebut yang menjadikan penentuan sebuah unit cost dengan tepat menjadi objek primer bagi para manajer di rumah sakit $^{12}$.Sedangkan di Indonesia berdasarkan PMK No. 59 tahun 2014 tarif pelayanan kesehatan di rumah sakit ditetapkan berdasarkan kesepakatan antara BPJS Kesehatan dengan Asosiasi Fasilitas Kesehatan dengan mengacu pada standar tarif INA-CBG's.

Berdasarkan penelitian beberapa negara berkembang dengan kondisi ekonomi menengah belum memiliki biaya unit cost rujukan dan sistem penetepan biaya pelayanan medis yang standar, sehingga setiap rumah sakit memiliki cara yang berbeda-beda dalam menetukan unit cost. Metode yang berbeda akan menghasilkan outcome yang berbeda pula. Masalah akan muncul ketika membandingkan efisiensi setiap metode, khususnya impikasi pada kebijakan kesehatan, metode penentuan unit cost yang standar diperlukan untuk pelaksanaan dan perancanaan asuransi kesehatan nasional. Hasil dari analisis biaya unit rumah sakit dapat mempengaruhi estimasi anggaran. Anggaran yang sesuai akan mempengaruhi manajemen keuangan rumah sakit dan juga keberlangsungan program asuransi nasional ${ }^{14}$.

\section{SIMPULAN}

Biaya satuan pelayanan eksisi fibro adenoma mammae di RS PKU Muhammadiyah Yogyakarta yang dihitung dengan metode activity based costing adalah sebesar Rp 4,704,877

Terdapat perbedaan biaya antara dengan metode $\mathrm{ABC}$, perhitungan rumah sakit dan tarif INA CBG dengan rincian sebagai berikut: besar perhitungan RS adalah Rp 4,431,420 sedangkan perhitungan dengan metode ABC didapatkan sebesar Rp 4,704,877 sehingga didapatkan selisih biaya Rp 273,457; Tarif INACBG's Rp 5,384,348 bila dibandingkan dengan perhitungan RSmaka perbedaan biayanya adalah $\mathrm{Rp}$ 952,928, sedangkan apabila tarif INA-CBG dibandingkan dengan unit cost metode $\mathrm{ABC}$ terdapat perbedaan sebesar Rp 679,471.

\section{DAFTAR PUSTAKA}

1. Permenkes, RI, 2014, Undang-undang Nomor 27 Tahun 2014, Menteri Kesehatan RI,Jakarta. program JKN. 
2. Peraturan Menteri Kesehatan RI No 59 tahun 2014 tentang Standar Tarif dalam Jaminan Kesehatan Nasional

3. Horngren, C.T., Datar, S.M., Foster, G., 2008, Akuntansi Manajemen, Jakarta: Salemba Empat.

4. Sperber. Et al., 2003, Diagnosis and Treatment of Breast Fibroadenomas by Ultrasound-Guided Vacuum-Assisted Biopsy. JAMA Surgery : Vol 138, no. 7 , hh. 796-800.

5. World Health Organisation, 2012, Breast cancer : Estimated Incidence, Mortality and Prevalence Worldwide in 2015.

6. Profil Kesehatan Indonesia. 2013. Fibroadenoma Mammae pada Remaja Indonesia. Diakses pada Agustus 2015, dari alamat http://kesehatan_reproduksi.remaja.org.html/.

7. Mulyadi. 2007, Edisi 6, Activity Based Costing Sistem Informasi Biaya untuk Pemberdayaan Karyawan, Pengurangan Biaya, dan Penentuan Secara Akurat Cost Produk dan Jasa, Yogyakarta: UPP STIM YKPN.

8. Alatas, H., 2012, Peran Dokter Spesialis dalam Efisiensi Pelayanan Pasien Jamkesmas Rawat Inap di RUmah Sakit Umum Daerah Banyumas, Tesis, Universitas Jendral Soedirman, Purwokerto.

9. Data Jumlah Pegawai Rumah Sakit PKU Muhammadiyah Yogyakarta Tahun 2014

10. Peraturan Menteri Kesehatan Rpublik Indonesia Nomor 340 Tahun 2014 Tentang Klasifikasi Rumah Sakit.

11. Goldberg, M dan Kosinski, L. 2011. Activity-Based Costing and Management in a Hospital-Based GI Unit. Clinical Gastroenterology And Hepatology: Vol. 9, pp 947-949

12. Popesko, Boris. 2013. Specifics of the Activity-Based Costing applications in Hospital Management.
International Journal of Collaborative Research on Internal Medicine \& Public Health: vol. 5, no. 3, pp 179-157

13. Peraturan Menteri Kesehatan RI No 59 tahun 2014 tentang Standar Tarif dalam Jaminan Kesehatan Nasional

14. Riewpaiboon, A. et al. 2007. Effect of costing methods on unit cost of hospital medical services. Tropical Medicine and International Health: vol. 12, no. 4, pp 554-563

15. Rosen, PP. 1996, Fibroepithelial neoplasms. Rosen PPed.Rosen's Breast Pathology. 1st ed. New York, NY Lippincott-Raven Press;143- 155.

16. Greenberg, et al., 1998, Management of fibroadenoma. J Gen Intern Med.;13640- 643

17. Hughes LE., Mensel RE., Webster DJT. 1987, Aberrations of normal development and involution: a new perspective on pathogenesis and nomenclature of benign breast disorders. Lancet.;21316- 1319.

18. Hughes LE, et al., 1999, Fibroadenoma and related tumors. Benign Disorders and Diseases of the Breast Concepts and Clinical Management 2nd ed. Philadelphia, Pa WB Saunders;73- 94.

19. Cole-Beuglet, et al., 1983. Fibroadenoma of the breast sonomammography correlated with pathology in 122 patients. AJR Am J Roentgenol.1983;140369- 375.

20. Shen, et al., 2015. A multi-centre randomised trial comparing ultrasound vs mammography for screening breast cancer in high-risk Chinese women. British Journal of Cancer : Vol.112, pp. 998-1004.

21. Dixon, JM, et al., 1996. Assessment of the acceptability of conservative management of fibroadenoma of the breast. Br J Surg.;83264- 265. 